\title{
Prevalence of Early Childhood Caries in South Africa: Protocol for a Systematic Review
}

Faheema Kimmie-Dhansay $^{1^{*}}$, BSc, BChD, MSc; Robert Barrie ${ }^{2^{*}}, \mathrm{BChD}, \mathrm{MChD}$, PhD; Sudeshni Naidoo ${ }^{2^{*}}$, BDS, LDS (RCS), MDPH, DDPH (RCS), MChD, PhD, DSC; Tina Sharon Roberts ${ }^{3 *}$, BChD, MChD, PhD

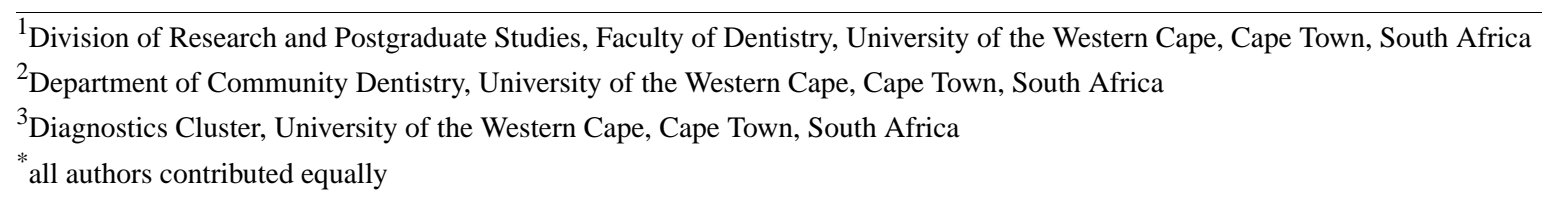

\section{Corresponding Author:}

Faheema Kimmie-Dhansay, BSc, BChD, MSc

Division of Research and Postgraduate Studies

Faculty of Dentistry

University of the Western Cape

Private Bag X17

Bellville

Cape Town, 7535

South Africa

Phone: 270219373030

Email: fkimmiedhansay@uwc.ac.za

\begin{abstract}
Background: Young children are at the highest risk of developing dental caries as they have a lack of autonomy over their diet and oral hygiene practices. Dental caries develops over time due to demineralization of tooth substance (enamel), which results from acid production during sugar metabolism by bacteria. Early onset of dental caries often results in asymptomatic presentation, but if left untreated, it can result in severe pain, infection, and dentoalveolar abscesses. Early childhood caries (ECC) is defined as dental caries in children aged 6 years and younger and is a significant public health problem in South Africa. According to the Global Burden of Disease study, untreated dental caries of primary teeth affects 532 million children. Untreated dental caries has many detrimental effects which can affect the physical development and reduce the quality of life of affected children. Furthermore, long-term untreated dental caries can result in school absenteeism, low BMI, and poor educational outcomes.
\end{abstract}

Objective: The purpose of this study was to determine the prevalence and severity of ECC in South Africa in children under the age of 6 years.

Methods: All cross-sectional studies documenting the prevalence and severity of dental disease (decayed, missing, and filled teeth scores) will be included. Various databases will be searched for eligible studies. Only studies conducted on South African children aged 6 years and under will be included. There will be no restriction on the time or language of publication. The quality of all eligible studies will be analyzed by a risk of bias tool developed by the Joanna Briggs Institute. The results will be presented narratively, and if possible, a meta-analysis will be conducted.

Results: The protocol is registered with PROSPERO. The literature search was initially conducted in November 2018 and was repeated in November 2020.

Conclusions: The results of this study will be used to advise stakeholders of the prevalence and severity of dental disease in children under 6 years of age in South Africa.

Trial Registration: PROSPERO CRD42018112161; https://www.crd.york.ac.uk/prospero/display_record. php?ID=CRD42018112161

International Registered Report Identifier (IRRID): DERR1-10.2196/25795

(JMIR Res Protoc 2021;10(8):e25795) doi: 10.2196/25795 


\section{KEYWORDS}

dmft; prevalence; dental caries; South Africa; early childhood caries

\section{Introduction}

Early childhood caries (ECC) is a significant public health problem in children aged 6 years and under living in South Africa [1]. According to the Global Burden of Disease study, the prevalence of untreated dental caries in primary teeth is 532 million [2].

Untreated dental caries has many adverse effects that can affect physical development, including increased absenteeism from school [3], low BMI [4,5], negative educational outcomes [3], and poor oral health-related quality of life $[6,7]$.

Children are at the highest risk of developing dental caries as they are vulnerable and depend on their caregivers for their dietary needs and oral hygiene. Dental caries develops over time and is a consequence of the demineralization of tooth enamel by acids produced during the metabolism of sugars by cariogenic bacterial sugars [8]. The early stages of the disease are often asymptomatic, but if left untreated, dental caries can result in severe pain and life-threatening infections.

Global statistics show an inconsistent prevalence of ECC between different continents and within the same country. In 2007, the prevalence of ECC in children under 5 years of age was $40 \%$ in Brazil [9], and in 2016, it varied between $41.9 \%$ and $16 \%$ in 2 separate districts in India [10,11]. Ismail and Sohn [12] conducted a systematic review in China and reported that the prevalence of ECC in the country was between $78.6 \%$ and $85.5 \%$. A later study by Zhang et al [13] recorded prevalence rates between $0.3 \%$ and $70.7 \%$ in children aged $1-6$ years in the same country.

The most recent prevalence rate of ECC in China was documented by Zeng et al [14], who recorded it to be $49.13 \%$ in preschool children between ages 3 and 5 years in a southeast Chinese province. Similar varying prevalence rates were recorded across continents (ranging from $22.9 \%$ in India to $90 \%$ in Indonesia) [15].

African countries have also shown varying prevalence of ECC: In Burkina Faso, Mazza et al [16] recorded a prevalence rate of $16.6 \%$ and in Nigeria, Folayan et al [17] reported an ECC prevalence rate of $6.6 \%$. Higher but inconsistent prevalence rates were documented in Sudan (52.4\% [18] and 71.4\% [19]), whereas in Uganda, 64\% of 3-5-year-old children had ECC [20].

In South Africa, the national prevalence rate of ECC is $60 \%$ among children under 6 years or age [1]. The prevalence of dental caries in children aged between 2 and 4 years in Johannesburg was $47.74 \%$ [21], whereas in the Western Cape, this varied from $71.6 \%$ [22] to $80 \%$ [23].

For the allocation of resources necessary to manage ECC effectively, it is important to understand the demographics of South Africa. The country is inhabited by 55.7 million people, among which $10.3 \%$ are under the age of 5 years [24]. Approximately $20 \%$ of children reside with either a grandparent or a caregiver [25], and $13.1 \%$ of households live in informal dwellings. Many families lack access to basic amenities including electricity, clean water, food, and a stable income [26] and more than one-quarter of the population rely on social grants, particularly in the poorest provinces [25]. Furthermore, the prevalence of HIV in the country was estimated to be $13.1 \%$ in 2018 [24]. With the high level of poverty, lack of access to infrastructure, and high HIV prevalence, the prevention of ECC has not been a priority in this country.

The purpose of this study was to determine the prevalence and severity of ECC in South Africa in children under 6 years of age. To date, this will be the first scientifically conducted systematic review on the prevalence of ECC in South Africa.

\section{Methods}

\section{Study and Ethics Approval}

This protocol will be conducted using the PRISMA-P (Preferred Reporting Items for Systematic reviews and Meta-Analyses for Protocols) guidelines [27]. Ethics approval was not required as this is not a primary study involving participants. The study protocol was registered with PROSPERO (CRD42018112161) on November 21, 2018.

\section{Study Eligibility Criteria}

\section{Types of Studies}

Cross-sectional and cohort studies reporting the prevalence of ECC in healthy children aged 6 years and under living in South Africa will be included in the review. This is a prevalence/incidence study, and consequently, no interventions will be assessed. The primary outcome is the prevalence/incidence and severity of ECC. The severity of ECC will be measured using the WHO guidelines in infants and children up to the age of 6 years. The WHO criteria include dmft scores (decayed, missing, and filled teeth; lower case indicates deciduous teeth) and the percentage of children that are caries free (including noncavitated caries [white spot lesions]).

\section{Information Source and Search Strategy}

Databases such as PubMed/MEDLINE, Cochrane, Scopus, Academic Search Complete, Dentistry and Oral Science, CINAHL, and ScienceDirect will be searched. Each database will be examined using tailor-made search terms or MeSH terms: (1) "early childhood caries" OR "caries" OR "decay" OR "dmft" OR "dental” OR "oral" OR PUFA; (2) "prevalence"; (3) “children” OR "peri-natal” OR “paediatric" OR "pediatric” OR neonatal OR infant; (4) South Africa. The keywords were used in the following combinations: $1+2+3+4$.

Scientific articles published in all South African official languages will be included in the review. Non-English articles will be translated by the Department of Foreign Languages, University of the Western Cape or a reputable translation company. To authenticate the translations, we will 
cross-reference the original article with the English abstract (which is usually available online) and reverse translations will be conducted to ensure its correctness.

Commentaries/letters and other gray literature will be excluded from this review.

Secondary searching (PEARLing) will be conducted (PEARLing is a search strategy where the reference lists of all the studies, whether included or excluded, are identified for possible inclusion). Manual searching will not be conducted due to the difficulty in replicating this method.

\section{Study Selection}

The articles will be uploaded into Rayyan [28] and screened in 2 stages. Two review authors (FK-D and TR) will independently assess the titles and abstracts of the studies and compare them against the inclusion criteria. The full texts of eligible papers and those that contain insufficient information will be sourced.

Other reviewers will be consulted when a disagreement pertaining to the inclusion of a publication arises. The searching process will include all prevalence studies up to November 15, 2020. All eligible studies will be included, and authors will be contacted if any clarification is needed.

After reading the full-text articles, those that do not meet the inclusion criteria will be discarded and the reasons will be recorded in the "Characteristics of excluded studies" table. The reference list of all included publications will be reviewed for additional eligible studies.

\section{Data Extraction and Management}

Two reviewers (FK-D and TR) will independently extract data onto a standardized data extraction form (initially piloted on a small sample of studies) using Microsoft Excel (2014). Upon completion of data collection, the data will be uploaded to the University of the Western Cape's data repository for safekeeping [29]. The data will be pilot tested, and the independent authors will be trained on how to extract data. The content of the form will be compared, and any differences in opinion will be resolved by discussion and consultation with the other reviewers. If any information from the studies is unclear or missing, the corresponding authors of the original papers will be contacted (where feasible). Study information will include author, title, year of publication, study design, and year in which the study was conducted. Participant-level data will include age, the province where the study was conducted, dmft score and standard deviation, number of cases and total sample size, and urban/rural setting. Pooled prevalence will be obtained by dividing the number of participants with the caries with the number of participants in the whole population, and the data will be assessed using Stata (StataCorp LLC). Pooled standard deviations will be calculated using the Cohen (1998) formula [30].

\section{Availability of Data and Materials}

All data, irrespective of the quality of publication, will be included in the review. If details on study publications cannot be obtained, a librarian will be consulted, and if the study remains non-obtainable, it will not be included in the qualitative or quantitative analysis.

\section{Study Quality and Risk of Bias Assessment}

The quality assessment of studies will be conducted using the Joanna Briggs Institute (JBI) Critical Appraisal Checklist for Studies Reporting Prevalence Data [31].

\section{Analysis of Study Findings}

A meta-analysis will be conducted, using Stata 17, if there are studies of similar comparisons reporting the same outcomes using a random-effects model and only if there are 4 or more studies.

\section{Assessment of Heterogeneity}

This review will include diverse modalities of interventions and will result in heterogeneity of the content of interventions, outcomes, and outcome measures. We will contemplate the feasibility of conducting a meta-analysis on a subgroup of included studies once the data have been extracted. Where feasible, we will assess the statistical heterogeneity in the meta-analysis by visually inspecting the scatter of effect estimates on the forest plots, Cochran test (using .10 level of significance), and by using the $I^{2}$ statistic [32].

\section{Assessment of Reporting Biases}

Where possible, we will use multiple sources of data, including those from unpublished trials. Should a meta-analysis be conducted, we will assess publication bias according to the recommendations described in the Cochrane Handbook for Systematic Reviews of Interventions [32]. Reporting biases such as selective reporting, duplication, and language of publication will be investigated.

\section{Analysis of Subgroups or Subsets}

We will use a subgroup analysis to examine heterogeneity using Stata 17. This will include exploring the influence of factors such as participant age, province, and urban/rural status. If sufficient numbers of studies are included, a meta-analysis will be performed.

\section{Results}

This protocol was registered with PROSPERO in October 2018, and the electronic searches were completed by November 15 , 2020. The original search yielded 2247 articles.

\section{Discussion}

\section{Principal Results}

The study aims to assess the prevalence of dental diseases and its severity in children under the age of 6. The South African government does not regularly monitor the dental disease of children or adults. The last national oral health survey was conducted in 2004 in children only and adults were excluded [33]. There are plans to determine the disease prevalence and severity in South Africa in the next few years. Until then, this review will inform the dental and medical fraternity about the prevalence of ECC in South Africa. 


\section{Conclusions}

There are very few studies detailing the prevalence and severity of dental disease in young children in South Africa. It is imperative that we monitor the trends of dental disease in children to inform stakeholders of this burden. Dental disease is a noncommunicable disease, and is associated with childhood obesity and childhood diabetes. More efforts need to be made to prevent the onset of dental disease, and thus prevent the incidence of other noncommunicable diseases in the future leaders of South Africa.

\section{Conflicts of Interest}

None declared.

\section{References}

1. van Wyk PJ, van Wyk C. Oral health in South Africa. Int Dent J 2004 Dec;54(6 Suppl 1):373-377. [doi: 10.1111/j.1875-595x.2004.tb00014.x] [Medline: 15631099]

2. 2015 Maternal Mortality Collaborators G. Global, Regional, and National Levels of Maternal Mortality, 1990-2015. Obstetrical \& Gynecological Survey 2017;72(1):11-13. [doi: 10.1097/01.ogx.0000511935.64476.66]

3. El-Sayed M, Osman K, El NABI. Prevalence of dental caries and its impact on the academic performance of Sudanese basic school children, AL-Sahafa Residential Area (2013-2014). J Am Sci 2015;11(4):195-203 [FREE Full text]

4. Benzian H, Monse B, Heinrich-Weltzien R, Hobdell M, Mulder J, van Palenstein Helderman W. Untreated severe dental decay: a neglected determinant of low Body Mass Index in 12-year-old Filipino children. BMC Public Health 2011 Jul 13;11(1):1-9. [doi: 10.1186/1471-2458-11-558]

5. Janakiram C, Antony B, Joseph J. Association of Undernutrition and Early Childhood Dental Caries. Indian Pediatr 2018 Aug 15;55(8):683-685 [FREE Full text] [Medline: 30218516]

6. Barbosa Neves ET, Perazzo MF, Gomes MC, Martins CC, Paiva SM, Granville-Garcia AF. Perception of parents and self-reports of children regarding the impact of traumatic dental injury on quality of life. Dent Traumatol 2017 Sep 28;33(6):444-450. [doi: 10.1111/edt.12366]

7. Abanto J, Panico C, Bönecker M, Frazão P. Impact of demographic and clinical variables on the oral health-related quality of life among five-year-old children: a population-based study using self-reports. Int J Paediatr Dent 2018 Jan 01;28(1):43-51. [doi: 10.1111/ipd.12300] [Medline: 28370564]

8. World Health Organization. Sugars and Dental Caries. URL: https://www.who.int/news-room/fact-sheets/detail/ sugars-and-dental-caries [accessed 2021-07-26]

9. Ferreira S, Béria J, Kramer P, Feldens E, Feldens C. Dental caries in 0- to 5-year-old Brazilian children: Prevalence, severity, and associated factors. Int J Paediatr Dent 2007;17(4):289-296. [doi: 10.1111/j.1365-263X.2007.00831.x]

10. Koya S, Ravichandra KS, Arunkumar VA, Sahana S, Pushpalatha HM. Prevalence of Early Childhood Caries in Children of West Godavari District, Andhra Pradesh, South India: An Epidemiological Study. Int J Clin Pediatr Dent 2016;9(3):251-255 [FREE Full text] [doi: 10.5005/jp-journals-10005-1372] [Medline: 27843258]

11. Stephen A, Krishnan R, Ramesh M, Kumar VS. Prevalence of early childhood caries and its risk factors in 18-72 month old children in Salem, Tamil Nadu. J Int Soc Prev Community Dent 2015;5(2):95-102 [FREE Full text] [doi: 10.4103/2231-0762.155731] [Medline: 25992333]

12. Ismail AI, Sohn W. A Systematic Review of Clinical Diagnostic Criteria of Early Childhood Caries. J Public Health Dent 1999 Sep;59(3):171-191. [doi: 10.1111/j.1752-7325.1999.tb03267.x]

13. Zhang X, Yang S, Liao Z, Xu L, Li C, Zeng H, et al. Prevalence and care index of early childhood caries in mainland China: evidence from epidemiological surveys during 1987-2013. Sci Rep 2016 Jan 13;6(1):18897 [FREE Full text] [doi: 10.1038/srep18897] [Medline: 26758962]

14. Zeng L, Zeng Y, Zhou Y, Wen J, Wan L, Ou X, et al. Diet and lifestyle habits associated with caries in deciduous teeth among 3- to 5-year-old preschool children in Jiangxi province, China. BMC Oral Health 2018 Dec 20;18(1):1-9. [doi: 10.1186/s12903-018-0686-0]

15. Chen KJ, Gao SS, Duangthip D, Lo ECM, Chu CH. Prevalence of early childhood caries among 5-year-old children: A systematic review. J Invest Clin Dent 2018 Nov 30;10(1):e12376. [doi: 10.1111/jicd.12376]

16. Mazza C, Strohmenger L, Campus G, Cagetti M, Caruso F, Petersen P. Oral health status of children living in Gorom-Gorom, Oudalan District, Burkina Faso. Int J Dent;(May 2007) 2010:1-7. [doi: 10.1155/2010/597251]

17. Folayan MO, Kolawole KA, Oziegbe EO, Oyedele T, Oshomoji OV, Chukwumah NM, et al. Prevalence, and early childhood caries risk indicators in preschool children in suburban Nigeria. BMC Oral Health 2015 Jun 30;15(1):72 [FREE Full text] [doi: 10.1186/s12903-015-0058-y] [Medline: 26123713]

18. Elidrissi SM, Naidoo S. Prevalence of dental caries and toothbrushing habits among preschool children in Khartoum State, Sudan. Int Dent J 2016 Aug;66(4):215-220. [doi: 10.1111/idj.12223] [Medline: 27061284]

19. Abdul-Jalil HS, Abuaffan AH. Early Childhood Caries Prevalence in Sudanese Preschool Children. IJDE 2017;10(2):5-9. [doi: 10.21088/ijde.0974.6099.10217.1] 
20. Kiwanuka S. N., Åstrøm, A.N.Trovik, T. A.. Dental caries experience and its relationship to social and behavioural factors among 3?5?year?old children in Uganda. International journal of paediatric dentistry, , pp 2004;14(5):336. [doi: 10.1111/j.1365-263X.2004.00570.x]

21. Kalil A. Caries experience of preschool children in selected sites in Johannesburg. University of Witwatersrand ETD Repository;(April) 2017 Dec 31:19-21.

22. Mohamed N. An investigation of early childhood caries in the lower socio-economic areas surrounding Tygerberg Oral Health Centre in order to plan a community appropriate intervention strategy. University of the Western Cape ETD Repositiry;(November) 2014 Dec 31:59-61.

23. Peerbhay F, Barrie RB. The burden of early childhood caries in the Western Cape Public Service in relation to dental general anaesthesia: implications for prevention. SADJ 2012 Feb;67(1):14-6, 18. [Medline: 23189901]

24. STATSSA. Mid-Year Population Estimates. STATSSA Mid Year Population. 2018. URL: http://www.statssa.gov.za/ publications/P0302/P03022018.pdf [accessed 2021-05-27]

25. STATSSA. General Household Survey 2018. STATSSA:General Household Survey- 2018. 2018 Jun 01. URL: http://www. statssa.gov.za/publications/P0318/P03182018.pdf [accessed 2021-05-27]

26. STATSSA. Statistical Release. Published. 2016 Dec 1. URL: http://cs2016.statssa.gov.za/wp-content/uploads/2016/07/ NT-30-06-2016-RELEASE-for-CS-2016-_Statistical-releas_1-July-2016.pdf [accessed 2021-05-27]

27. Shamseer L, Moher D, Clarke C, Ghersi D, Liberati A, Petticrew M, PRISMA-P Group. Preferred reporting items for systematic review and meta-analysis protocols (PRISMA-P) 2015: elaboration and explanation. BMJ 2015 Jan 02;350:g7647 [FREE Full text] [doi: 10.1136/bmj.g7647] [Medline: 25555855]

28. Ouzzani M, Hammady H, Fedorowicz Z, Elmagarmid A. Rayyan-a web and mobile app for systematic reviews. Syst Rev 2016 Dec 05;5(1):210 [FREE Full text] [doi: 10.1186/s13643-016-0384-4] [Medline: 27919275]

29. KIKAPU Research Data Repository. URL: https://kikapu.uwc.ac.za/ [accessed 2021-07-26]

30. Glen S. Pooled Standard Deviation - Statistics How To. [online] Statistics How To. 2016. URL: https://www. statisticshowto.com/pooled-standard-deviation/> [accessed 2021-05-27]

31. Joanna Briggs Institute critical appraisal checklist for prevalence Studies. Joanna Briggs Institute. URL: https://joannabriggs. org/sites/default/files/2019-05/JBI Critical Appraisal-Checklist for Prevalence Studies2017 0.pdf [accessed 2021-05-27]

32. Higgins J. P. Cochrane handbook for systematic reviews of interventions. John Wiley \& Sons 2019 Dec 31:online.

33. van Wyk PJ, Louw AJ, du Plessis JB. Caries status and treatment needs in South Africa: report of the 1999-2002 National Children's Oral Health Survey. SADJ 2004 Jul 1;59(6):238-242. [Medline: 15457909]

\section{Abbreviations \\ ECC: early childhood caries \\ WHO: World Health Organization}

Edited by G Eysenbach; submitted $21.12 .20 ;$ peer-reviewed by C Janakiram; comments to author 25.05.21; revised version received
$27.05 .21 ;$ accepted $17.06 .21 ;$ published 03.08 .21
Please cite as:
Kimmie-Dhansay F, Barrie R, Naidoo S, Roberts TS
Prevalence of Early Childhood Caries in South Africa: Protocol for a Systematic Review
JMIR Res Protoc $2021 ; 10(8):$ e25795
URL: $\underline{\text { https://www.researchprotocols.org/2021/8/e } 25795}$
doi: $10.2196 / 25795$
PMID:

CFaheema Kimmie-Dhansay, Robert Barrie, Sudeshni Naidoo, Tina Sharon Roberts. Originally published in JMIR Research Protocols (https://www.researchprotocols.org), 03.08.2021. This is an open-access article distributed under the terms of the Creative Commons Attribution License (https://creativecommons.org/licenses/by/4.0/), which permits unrestricted use, distribution, and reproduction in any medium, provided the original work, first published in JMIR Research Protocols, is properly cited. The complete bibliographic information, a link to the original publication on https://www.researchprotocols.org, as well as this copyright and license information must be included. 